www.nature.com/hr

\title{
COMMENTARY
}

\section{Potential mechanisms in angiotensin II-induced EPCs senescence}

\author{
Toshio Imanishi \\ Hypertension Research (2011) 34, 989-990; doi:10.1038/hr.2011.84; published online 23 June 2011
}

$\mathrm{T}$ he discovery of endothelial progenitor cells (EPCs) offers novel therapeutic approaches for cardiovascular disease. ${ }^{1}$ The number of EPCs and their function are negatively affected by atherosclerotic risk factors. In addition, the prognostic value of the number of circulating EPCs has been reported. ${ }^{2}$ Currently, the number and function of EPCs may represent a cellular risk marker of vascular endothelial health.

Angiotenisn II (Ang II) increases oxidative stress, leading to endothelial dysfunction. We have shown previously that Ang II increases the rate of senescence of EPCs via the stimulation of superoxide formation. ${ }^{3}$ Inhibition of Ang II signaling by Ang II receptor blockers and angiotensin-converting enzyme inhibitors has been reported to increase the number of EPCs in patients with cardiovascular disease. ${ }^{4,5}$ It is likely that augmentation of the renin-angiotensin system may be involved in the pathogenesis of EPCs senescence, although the precise mechanism remains unsolved.

In this issue of Hypertension Research, Calò et $a .^{6}$ address the potential mechanisms in terms of Ang II-induced senescence of EPCs. They have studied patients with Bartter's/ Gitelman's syndrome (BS/GS) patients as a human model of blunted Ang II signaling, thus presenting a unique system to explore EPC biology and its relationship with vascular function (Figure 1). They show that EPC sub-populations characterized by $\mathrm{CD} 133^{+}$ kinase insert domain receptor $(\mathrm{KDR})^{+}$or $\mathrm{CD} 34^{+} \mathrm{CD} 133^{+} \mathrm{KDR}^{+}$cells and flow-mediated vasodilation were significantly correlated in BS/GS patients. They conclude that EPCs are sensitive to Ang II signaling and that this

$\mathrm{Dr} \mathrm{T}$ Imanishi is at the Department of Cardiovascular Medicine, Wakayama Medical University, 811-1 Kimiidera, Wakayama 641-8510, Japan.

E-mail: t-imani@wakayama-med.ac.jp should indeed impact on the number and function of the cells. Specifically, they propose that the increased number of EPCs and improved endothelial function in patients with BS/GS syndromes are closely related to upregulation of heme oxygenase-1 (HO-1) possibly through stimulation of calcitonin gene-related peptide (CGRP).

The authors consider several issues in the interpretation of their findings. The first issue is how EPC is defined. Cells positive for both CD34 and KDR, which has been adopted as a marker of EPCs, are able to proliferate and differentiate into mature endothelial cells. However, CD34 is expressed not only on EPCs, but also on mature endothelial cells. Currently, it remains to be unsolved whether or not double-positive cells for CD34 and
KDR, reflect true EPCs capable of vascular repair. ${ }^{7}$ EPCs are thought to consist of heterogeneous populations from a more primitive $\mathrm{CD} 133^{+} / \mathrm{CD} 34^{+} /$vascular endothelial growth factor receptor (VEGFR)- $2^{+}$subpopulation to a more mature $\mathrm{CD}_{133^{-}} /$ $\mathrm{CD} 34^{+} /$VEGF-R2 $^{+}$sub-population. ${ }^{8}$ Calò et al. demonstrate that in BS/GS patients, EPC populations, particularly $\mathrm{CD} 133^{+} \mathrm{KDR}^{+}$ and $\mathrm{CD}_{34}{ }^{+} \mathrm{CD} 133^{+} \mathrm{KDR}^{+}$, but not $\mathrm{CD} 34^{+} \mathrm{KDR}^{+}$cells, strongly correlate with both flow-mediated vasodilation and HO-1 gene expression. These data extend current knowledge of the heterogenous EPC population and may have implications for the treatment of vascular disease and arterial injury.

The second issue for consideration is how the increased HO-1 in BS/GS patients relates

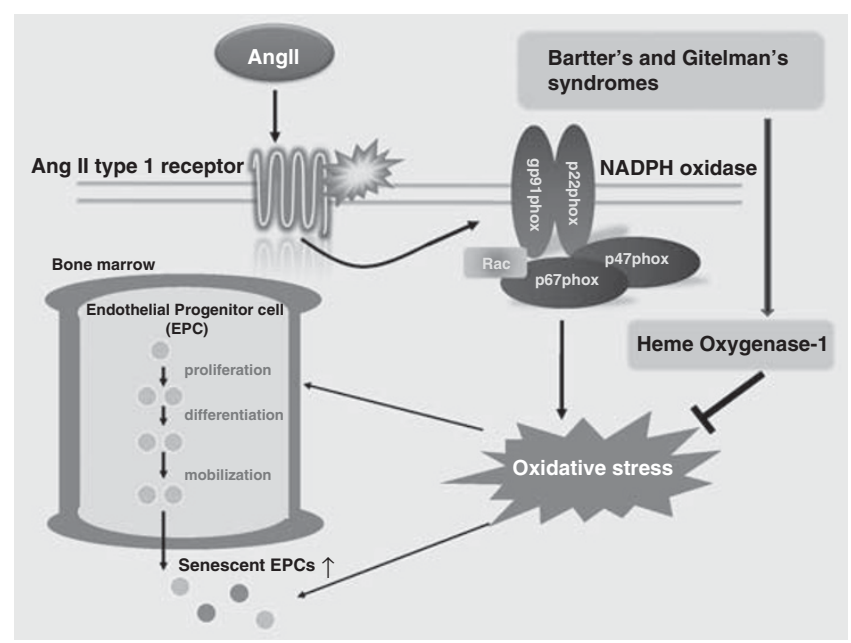

Figure 1 Ang II-induced EPC senescence in BS/GS syndromes. Ang II stimulates gp91 ${ }^{\text {phox }}$ expression, a subunit of NADPH oxidase, via the angiotensin type 1 receptor, which leads to superoxide formation. Oxidative stress caused by Ang II interferes with the ability of EPCs to proliferate, differentiate and mobilize in the bone marrow. Oxidative stress also induces EPC senescence. Patients with BS/GS syndromes, who may represent a human model of blunted Ang II signaling, have increased heme oxygenase-1 and reduced Ang II-stimulated oxidative stress, leading to an increased number and improved function of EPCs. 
to the increased number of EPCs. Calò et al. suggest the involvement of CGRP, which functions as an endogenous protector to counteract the senescence of EPC in hypertension. ${ }^{9,10}$ However, this remains to be clarified in relation to the mechanistic effects of HO-1 on CGRP production. It also remains unknown whether CGRP accelerates senescence of EPCs through telomerase-dependent or -independent mechanisms. In addition, the intracellular redox state in progenitor cells is a critical modulator of the balance between self-renewal and differentiation. It would be interesting to investigate the levels of antioxidants, such as manganese superoxide dismutase (MnSOD) and glutathione peroxidase-1 (GPx-1), in EPCs from BS/GS patients because competent EPCs have been reported to possess high levels of these antioxidants. ${ }^{11,12}$ Further investigation is required into the relationship between the intracellular redox state and the biological activity of EPCs as well as into the role of potential mediators, including CGRP.

\section{CONFLICT OF INTEREST}

The author declares no conflict of interest.

1 Asahara T, Murohara T, Sullivan A, Silver M, van der Zee R, Li T, Witzenbichler B, Schatteman G, Isner JM. Isolation of putative endothelial progenitor cells for angiogenesis. Science 1997; 275: 964-967.

2 Werner N, Kosiol S, SchiegI T, Ahlers P, Walenta K, Link A, Böhm M, Nickenig G. Circulating endothelial progenitor cells and cardiovascular outcomes. N Engl J Med 2006; 353: 999-1007.

3 Imanishi T, Hano T, Nishio I. Angiotensin II accelerates endothelial progenitor cell senescence through induction of oxidative stress. J Hypertens 2005; 23: 97-104.

4 Bahlmann FH, de Groot K, Mueller OH, Hertel B, Haller $\mathrm{H}$, Flister D. Stimulation of endothelial progenitor cells: a new putative therapeutic effect of angiotensin II receptor antagonism. Hypertension 2005; 45 : 526-529.

5 Min TQ, Zhu CJ, Xiang WX, Hui ZJ, Peng SY. Improvement in endothelial progenitor cells from peripheral blood by ramipril therapy in patients with stable coronary artery disease. Cardiovasc Drugs Ther 2004; 18 : 203-209.

6 Calò LA, Facco M, Davis PA, Pagnin E, Maso LD, Puato M, Caielli P, Agostini C, Pessina AC. Endothelial progenitor cells relationships with clinical and bio- chemical factors in a human model of blunted angiotensin II signaling. Hypertens Res 2011; 34: 1017-1022.

7 Dong C, Crawford I, Goldschmidt-Clermont PJ. Endothelial progenitor obsolescence and atherosclerotic inflammation. J Am Coll Cardiol 2005; 45: 1458-1460.

8 Yin AH, Miraglia S, Zanjani ED, Almeida-Porada G, Ogawa M, Leary AG, Olweus J, Kearney J, Buck DW. AC133, a novel marker for human hematopoietic stem and progenitor cells. Blood 1997; 90: 5002-5012.

9 Zhou Z, Peng J, Wang C-J, Li D, Li T-T, Hu C-P, Chen $X-P$, Li Y-J. Accelerated senescence of endothelial progenitor cells in hypertension is related to the reduction of calcitonin gene-related peptide. J Hypertens 2010; 28: 931-939.

10 Noble M, Smith J, Power J, Mayer-Proschel M. Redox state as a central modulator of precursor cell function. Ann NY Acad Sci 2003; 991: 251-271.

$11 \mathrm{He} \mathrm{T}$, Peterson TE, Holmuhamedov EL, Terzic A, Caplice NM, Oberley LW, Katusic ZS. Human endothelial progenitor cells tolerate oxidative stress due to intrinsically high expression of manganese superoxide dismutase. Arterioscler Thromb Vasc Biol 2004; 24: 2021-2027.

12 Dernbach E, Urbich C, Brandes RP, Hofmann WK, Zeiher AM, Dimmeler S. Antioxidative stress-associated genes in circulating progenitor cells: evidence for enhanced resistance against oxidative stress. Blood 2004; 104: 3591-3597. 